\title{
Cultural Diversity and its Impact on Organizational Goals: A Case Study of Quetta, Balochistan
}

\author{
Manzoor Ali ${ }^{1}$, Aftab Ahmed ${ }^{2}$, Ghulam Ali Mashori ${ }^{3}$, Nadir Ali ${ }^{4}$ \\ ${ }^{1,3}$ Department of Management Sciences, BUITEMS, Quetta \\ Email: manzoor.ali@buitms.edu.pk \\ Email: ghulam.ali@buitms.edu.pk \\ ${ }^{2}$ Department of Computer Science, BUITEMS, Quetta \\ Email: aftab.ahmed@buitms.edu.pk \\ ${ }^{4}$ Department of Petroleum \& Gas, BUITEMS, Quetta \\ Email: nadir.khoso@ buitms.edu.pk
}

\begin{abstract}
The research is about role of cultural diversity and its impact on the organizational goals. The Quetta comprises of multicultural dimensions like Balochs, Pakhtoons, Uzbeks, Sindhis, Punjabis etc. The Balochs and Pakhtoons are claiming that they are indigenous part of Quetta while other cultures are considered as settlers.

There always have been conflicts between Balochis and Pakhtoons on the local resources. The conflicts have developed a vacuum between both cultures. People from both cultures have positions in each sector of economy; therefore it often becomes difficult to work for common goals of organization.

The HRM has a difficult task to recruit the applicants as literacy rate in the region is relatively low. HRM has no option but to select applicants from diverse cultures which ultimately result in organizational conflict. Alternatively, organizations can recruit people from other provinces but high cost of recruitment and strong resistance from the local people are barriers to satisfy staffing needs.

This study includes main variables like cultural tolerance, cultural sensitivity, professional attitude, motivation and job security and team work. This region is rich in mineral resources but lack of coordination and co-operation among the work groups has made the organizations away to achieve their goals in most effective and efficient way.
\end{abstract}


Keywords: Cultural Belief, Cultural Diversity, Cultural Sensitivity, Cultural Tolerance, Team work

\section{Introduction}

\subsection{Culture}

Culture is group of people who share similar values and beliefs by living in particular society. Growing up in any society, people learn basic values from their families and make their behavior accordingly. Culture is best described by many authors. The first definition was given by Edward Burnett Taylor, a British anthropologist who gave his views about culture. He said "Culture includes knowledge, art, believe, law, art, morals, and other capabilities and habits acquired by man as a member of society" (Haviland, 1994).

Studying the different cultures, it has been observed that people are very sensitive about their cultures. In formal language this term is called as cultural sensitivity. Cultural sensitivity is strongly linked with cultural tolerance. More culturally sensitive people show less tolerance when negatively talked about their cultures. Organizations should be careful about cultural sensitivity and cultural tolerance while forming work teams. Proper formulation of team groups can ensure minimum conflicts among employees belong to different cultures.

The perception and attitude of employees working in any organization must be kept in consideration as it is very necessary to analyze that how individuals make perception for others. Diversity can be measured through different parameters. According to Eboni G. Price, "cultural diversity is consisting of psychological climate e.g. perception of racial/ethnic tension, behavioral dimension like quality and quantity of interactions across diverse groups". (Eboni G. Price, et al, 2005)

Culture in other words is combination of beliefs, values, languages and trends which are mostly shared within particular group. While cultural diversity is combination of different set of values. According to Cox, "cultural diversity is reflective of a distinct set of values, attitudes, language and practices that are shared among group members." (Cox, 2004). The different set of values from different cultures may be contradictory when people are working in one organization culture. The sense of respect and honor for other's culture may bring down the conflict up to minimum level.

This is very important to know the level of difference between the social cultures of employees working in particular organization. Employees identify the culture of their co-workers not only on the basis of language but also on other factors. According to Hayles and Russell "Cultural diversity may be defined in the terms of race, ethnicity and gender. However, in broader sense it is also explained in the terms of age, nationality, religion, lifestyle, physical appearance, economic status and other factors". (Hayles and Russell, 1997). 
Kossek and Label have defined cultural diversity as all the ways in which people differ, and it encompasses all the different characteristics that make one individual or group different to each other. (Kossek and Label, 1995)

To understand the organizational culture, managers should go for careful study of cultural diversity. In order to achieve the organizational goals managers must observe closely the work environment. According to Molly K. "there have been many changes in formation of organizational culture therefore it becomes necessary for leader and managers to understand the cultural diversity and its impact on the organization" (Molly K.1997)

In this research the cultural diversity is creating problem for the organizations as it has been observed that there is less tolerance and high cultural sensitivity among different ethnic groups in Balochistan. However, cultural diversity ensures best result for organization as people from diverse cultures can bring more skills and qualification for organizational jobs. According to Robin J. and David A. "When group members share common goals and values within organizations, cultural diversity leads to more beneficial outcomes." (Robin J. and David A. 2001).

\subsection{Culture of Quetta}

Quetta is considered as largest city of Balochistan Province. It is also capital city and comprises of multicultural values. The city is consisting of different tribes like Pakhtoon, Baloch, Hazara, Sindhi, Punjabi and different others. In cultural terminology the culture of this city is Salad Bowl. Majority of population is consisting of Pakhtoons, Balochs and Hazaras.

From geographical point of view, Quetta is divided in two major areas named as Pakhtoon and Baloch belts. The Pakhtoon belt includes Chaman, Pishin, Loralai, Qilla Abdullah, Qilla Saifullah while Baloch belt consisting of Khuzdar, Kalat, Mastung, Sibi and other cities.

During the Afghan Russia war, many Afghan migrants came to Balochistan and permanently settled in cities like Chaman, Pishin, Loralai and other areas of Pakhtoon belt. Afghan people brought culture of their own and now majority of people have adopted the Afghani culture in Pakhtoon belt. The food, Music, lifestyle and many other cultural trends have been borrowed by local people from Afghan Culture. Pakhtoon belt consisting of tribes like Achakzai, Kakar, Kasi etc. and they mostly speak Pashto language in Pakistan and Afghanistan.

The Baloch culture is old and rich in terms of its values, customs, traditions and life style. Balochi Music is very popular not only in Balochistan but throughout Pakistan. Originally Balochs are from Iran and practice same type of cultural values as their ancestors were performing in Iran and other different parts of world. The Baloch tribes are consisting of Bugti, Marri, Mazarrai, Jamali, Bizanjo etc. People living in the Baloch belt have multi linguistic skills and can speak many languages. As many people live near border areas of Sindh province therefore, they can also speak Sindhi language. 


\section{Research Methodology}

The research is Causal and Quantitative in nature. In order to measure the impact level of cultural diversity, the researcher has used correlation, a statistical tool which comes under quantitative techniques of the research. Relating to nature of study, researcher has identified some variables through which cultural diversification and its impact on organizations operating in Quetta can best be illustrated. These variables are cultural tolerance, cultural sensitivity, professional attitude, motivation and job security and team work. The researcher has collected data through structured open-ended and close-ended questionnaire from the people who are working in Banking, Educational and Non-Government Organizations (NGOs) sector. As majority of employees are working in these organizations, therefore research has taken sample for response from these sectors. While collecting the data researcher has taken almost equal sample of both Pakhtoon and Baloch people working in different sectors of the economy inside the Quetta. The proper ratio of women workers is also included in the study. As the main purpose of this research is to find out the impact of cultural diversity on organizations working within the Quetta, therefore, both tribes Pakhtoons and Balochis who are in majority are mostly taken into sample. However, other tribes who are in minority like Hazaras, Punjabis, Sindhis etc. are also included in the sample for the best identification of problem. The total number of employees working in Banking, Educational and NGOs sector is approximately 2500. The sample of 20 percent is taken for the best representation of the population and proper identification of the matter. The questionnaires were distributed among the employees working in three sectors and belong to different ethnic groups or tribes. For the best understanding of the matter, researcher also conducted the in-depth interviews from the sample.

\subsection{Sample Size and sample Method}

The total population of Banking, Educational and NGOs sector is approximately 2500 in the region. For the proper representation, $20 \%$ of sample is taken. Researcher has made it clear that there should be equal representation from three sectors. The questions were asked relating to cultural tolerance, cultural sensitivity, professional attitude, motivation and job security and team work. The data analysis is done through using SPSS software and MS-Excel. The convenient sampling method is used for the study as geographical area was scattered.

\subsection{Data Analysis}

\subsubsection{Cultural Tolerance}

Talking about cultural tolerance, researcher asked questions regarding attitude of employees feeling comfort to work with other cultural groups, employee's 
statements about favoring or not to other groups in organization. In addition to that, attitude was also measured relating to creation of good relations to employees of diverse cultures. Following result show the level of cultural tolerance among the employees working in three sectors.

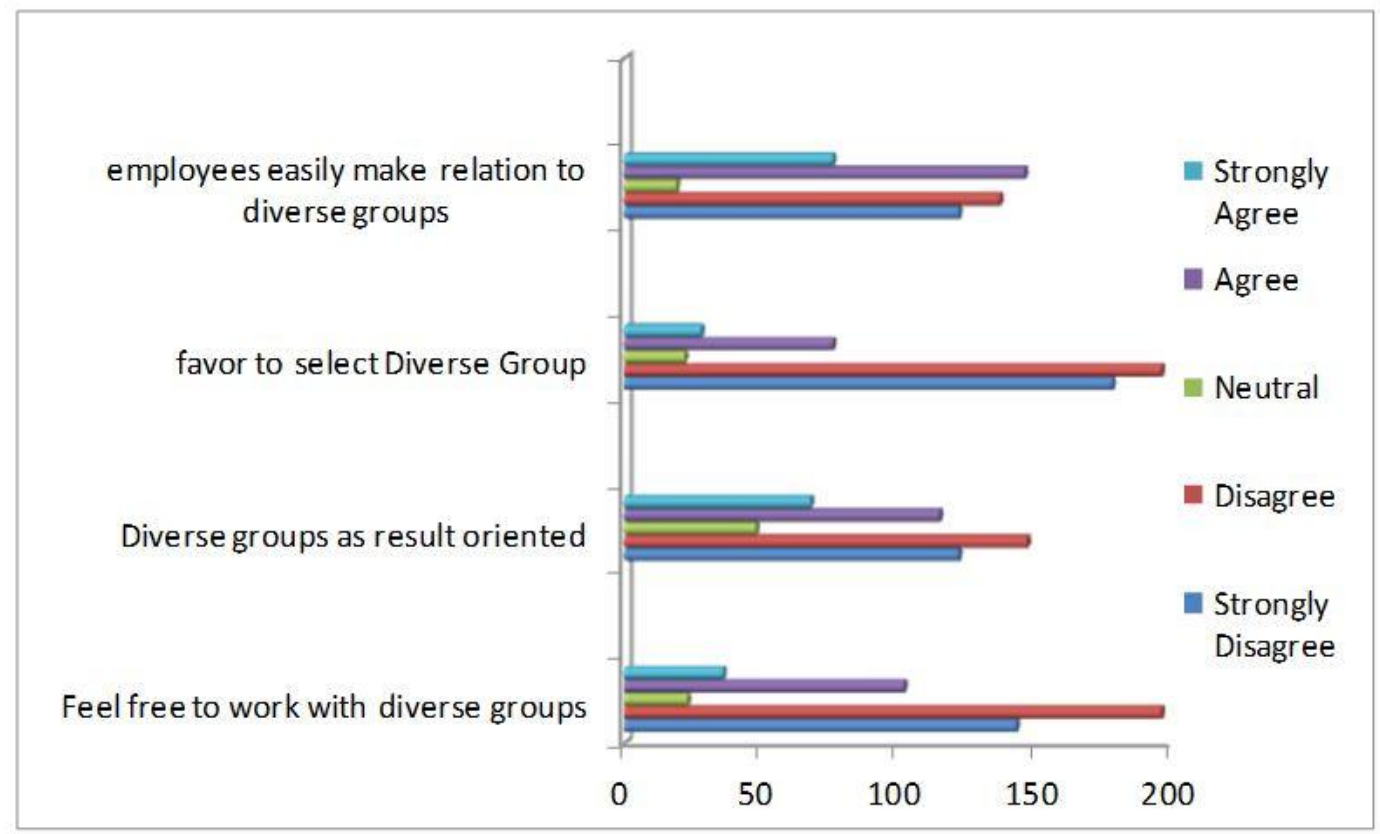

Fig 1. Cultural Tolerance

Approximately $68 \%$ people disagree with the statement that they feel free to work with people of diverse culture. When asked the reason, they responded that a person can work in better way with that employee(s) who is belonging from his/her community as they can easily understand the language of each other. However, researcher knows that people living in the Quetta can speak multiple languages like Pashto, Balochi, and Urdu etc.

Researcher also collected the opinion of respondents regarding performance of employees of diverse cultures. Approximately 54\% percent of people argued against the statement that employees of diverse cultures are result oriented. However, it is very difficult to determine the role of any single community for organization's success.

Majority as $75 \%$ of employees submitted responses against the selection of employees from diverse cultures. According to their opinions, there must be one social culture in organization which will lead to smooth working of organization. However, literature suggests that diversity brings prosperity and success for organization in long run.

It is also very difficult for the employees to make long term and healthy relations with their colleagues of diverse cultures. Majority of employees almost $52 \%$ were reluctant to make long relations as they were of view that relation must be limited 
up to organization. However they responded that all employees should avoid from conflict as it can be harmful for smooth functioning of organization.

\subsubsection{Cultural Sensitivity}

The second important variable of the study was cultural sensitivity. The cultural sensitivity can best be referred as level of emotional link with one's cultures. The researcher asked questions relating to conflict resolution, feedback from diverse employees, acknowledgement from other groups and possibility of expressing derogatory remarks for employees belonging to other culture. The first two questions relating to conflict resolution and feedback from employees of other cultures has shown high cultural sensitivity by the respondents. While subsequent two questions shows average and low cultural sensitivity.

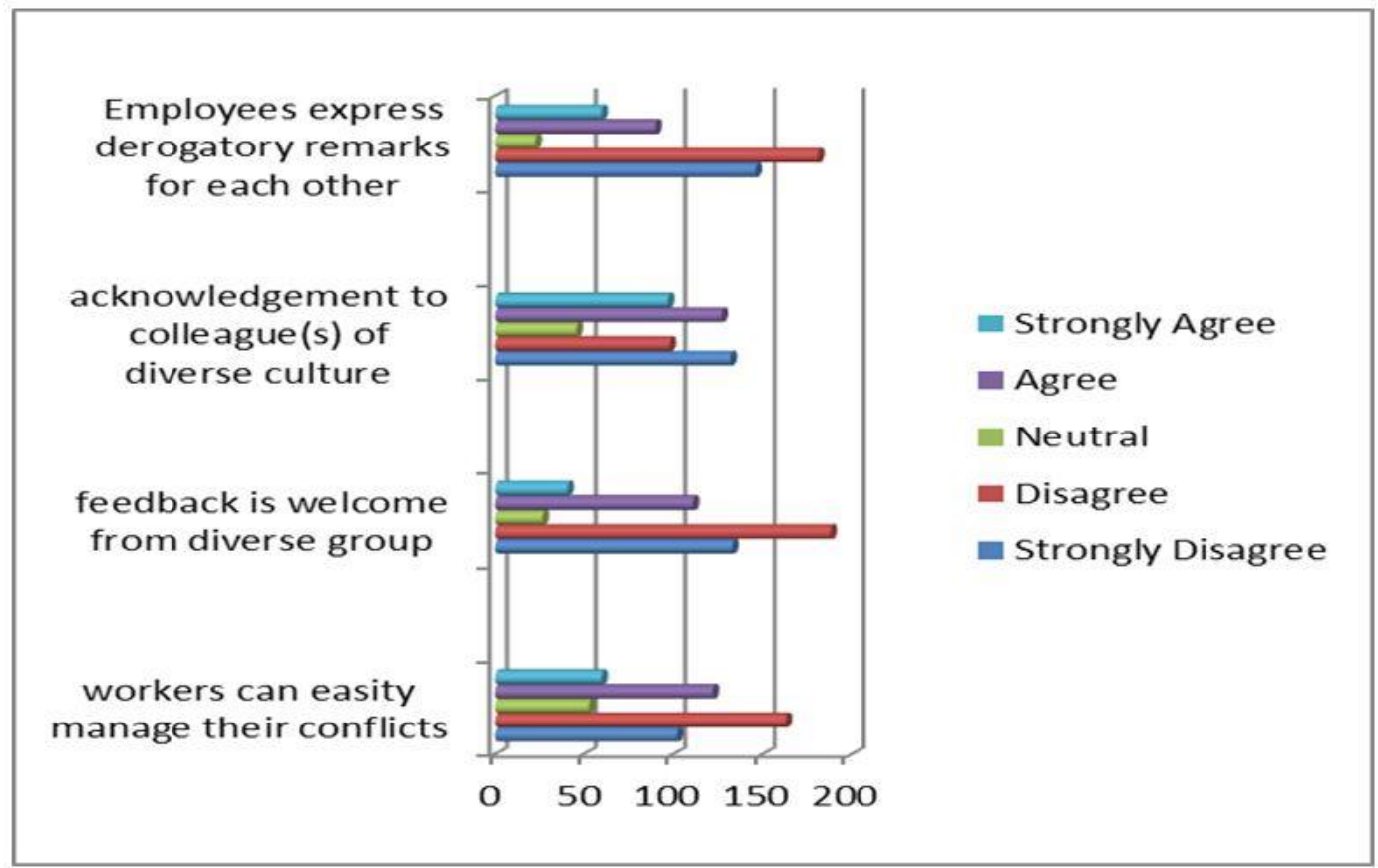

Fig 2. Cultural Sensitivity

The graph clearly shows that workers can't easily solve their conflicts as about $55 \%$ of respondents were disagree with the statement that employees can solve problems of their own. However, during the interview employees said those conflicts are often solved by mediators. The main hurdle in solving conflicts is ego hold by different communities. Employees also responded against the statement that they always welcome the feedback from employees of other cultures. When asked why they are reluctant to receive feedback, they responded that people from diverse cultures have always complaints from them which are often based on emotional factors; therefore they consider their feedback as irrational. Approximately 64\% employees said that we don't welcome any feedback from employees of other cultural groups. However, $30 \%$ respondents 
said that they welcome all type of feedback from all employees for better working relations and proper co-ordination.

Talking about the acknowledgement, employees almost equally response in favor and against of the statement that they acknowledge their colleagues. Approximately $46 \%$ of respondents said they don't acknowledge their employees belonging to other cultures because they have never received acknowledgment from them. However $45 \%$ respondents said that they acknowledge to their colleagues of diverse culture. This shows that there is almost equal response in the terms of acknowledgment from different communities.

Employees were reluctant that they express derogatory remarks about their colleagues as majority almost $65 \%$ of respondents said that they avoid doing so. This response shows a particular level of respect for other's culture.

\subsubsection{Professional Attitude}

Under this variable, researcher asked questions regarding co-operation of employees within organization, readiness of employees to perform their services as mentor for other cultural groups, respect for diverse culture and wiliness to work with any supervisor of diverse culture.

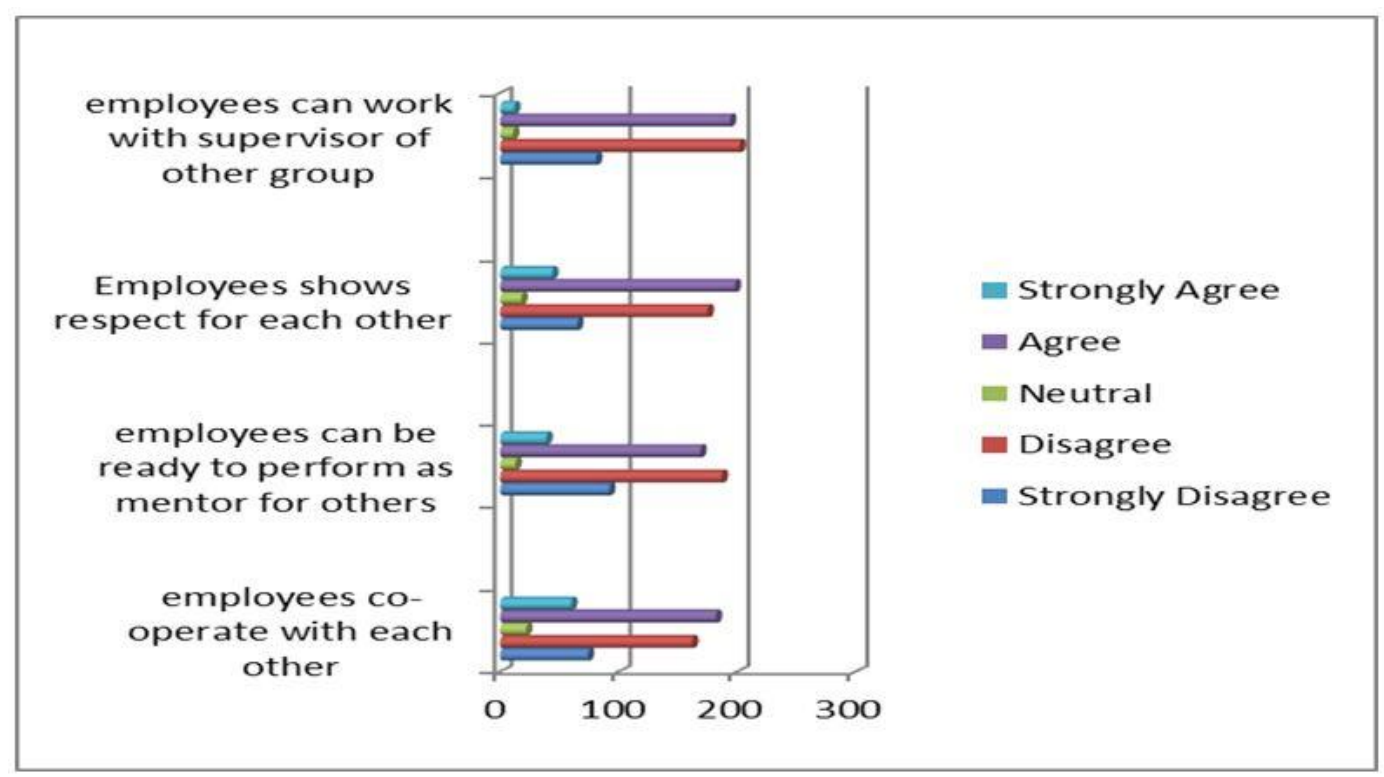

Fig 3. Professional Attitude

Employees showed almost equal responses relating to co-operation among them. Approximately $48 \%$ of respondents from different sectors said that they always show co-operation for the colleagues of diverse cultures However, $47 \%$ of respondents went against the statement that they have co-operation within the organization.. On the other hand, many respondents submitted that they will not perform their services as mentor for people of other groups. Almost 56\% of 
respondents were reluctant to be mentor for employees of diverse cultures. However, $41 \%$ of employees were ready to be mentor for the employees.

The researcher found almost equal responses when asked about respect shown by employees for each other's culture within organization. Approximately $48 \%$ of employees went against the statement and said that they consider the respect shown from other cultural groups as artificial and necessity of particular time. The same ratio of respondent as $48 \%$ told the researcher that they have respect for other people and their culture. However, $4 \%$ of employees remain neutral.

Respondents were also reluctant to work with supervisor of diverse cultures as majority almost $57 \%$ said that people from other group often mistreat them; shows anger and assign tough targets to them. These factors often pursue them not to work under supervision of person of diverse culture. However, $41 \%$ of employees said that they are ready to work under supervision of any person of diverse culture.

\subsubsection{Motivation and Job Security}

Respondents were asked certain questions regarding to their motivation and job security by working with diverse groups within organizations. The questions were related to job security, equal employment opportunities, merit promotion and skill improvement by working with other groups. The graph shows the complete picture of responses relating to variables.

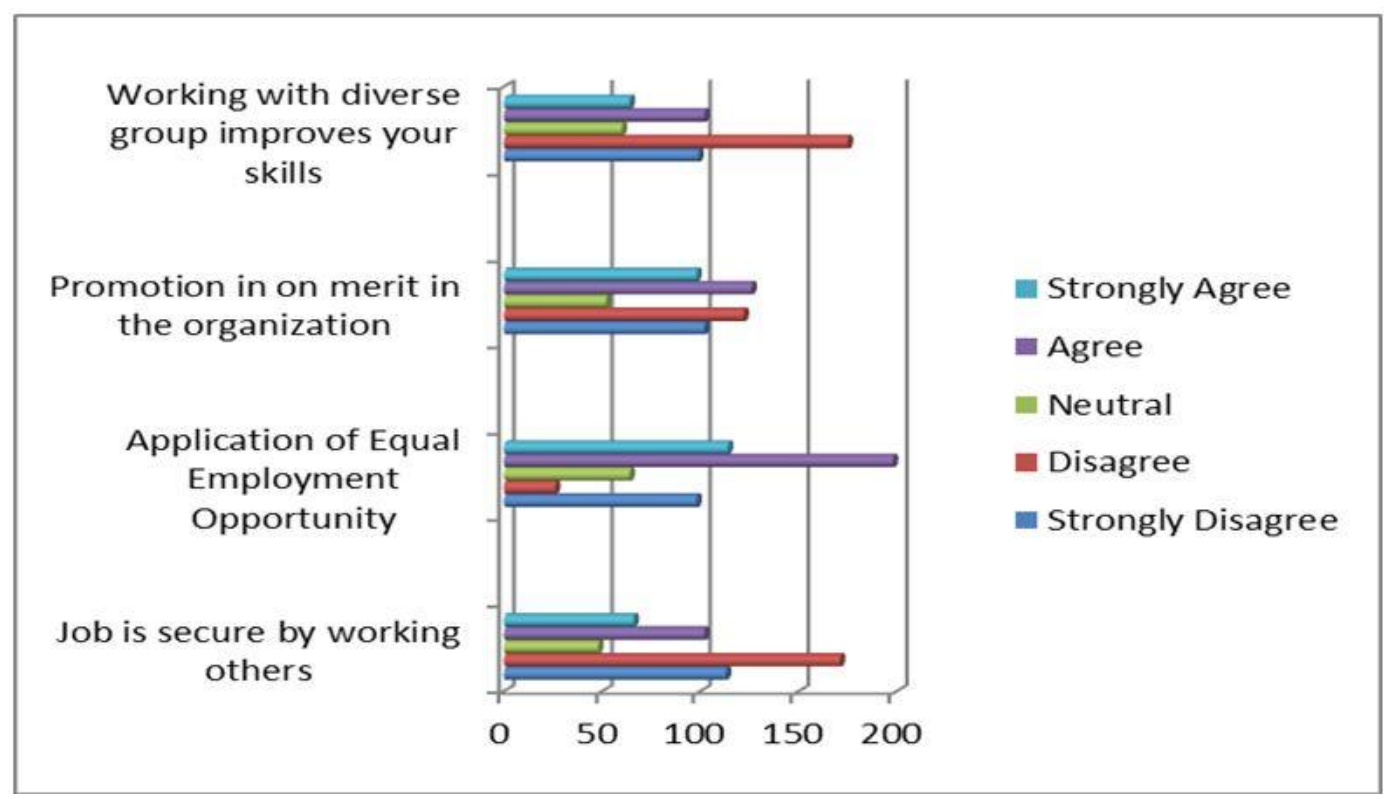

Fig 4. Motivation and Job Security

Respondents were asked about their job security in those organizations where employees from diverse cultures are working. Almost $57 \%$ of respondents said that they feel insecure to work with diverse groups. The reason behind the 
argument was that some cultural groups are less educated when compare them with other groups; therefore less educated people feel threat to be selected for organizational jobs. However majority of respondents said that Equal Employment policies and applications are practicing in their organizations. Talking about promotion on merit, employees were equally distributed as $45 \%$ of employees said that promotion is on merit, and almost same percentage of respondents went against the statement. However, $10 \%$ of respondents remained neutral. Additionally, question was asked about improvement of skills by working with people of diverse groups. The majority almost $55 \%$ of respondents said that they work has been improved on their personal efforts and there is no contribution of people from diverse groups.

\subsubsection{Team Work}

Employees were asked different questions relating to team work in order to know the level of co-operation and co-ordination among them. The questions were related to sense of achievement of common goals, co-ordination, negotiations within groups, collaborative work, resolution of conflicts, listening of each other's ideas and support by team members to each other by performing their duties.

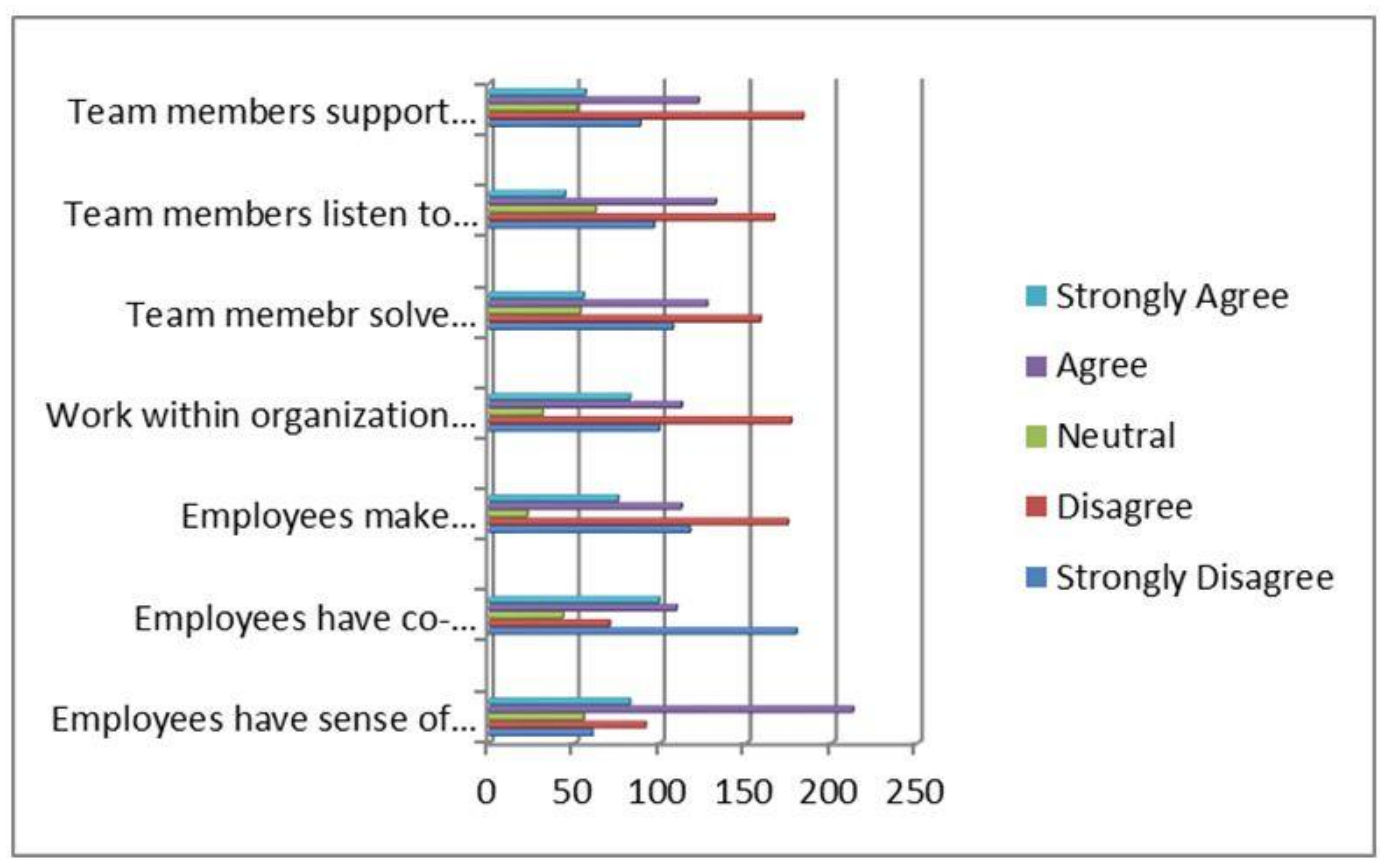

Fig 5. Team Work

Majority of repondents said that employees have sense of spririt for achieving organizational goals. They were of view that organization sustainability can lead to their economic survival therefore they are working with strong spirit to lead the organization towards profitibility. Majority almost 59\% respondents said that they 
are passionate to achieve organizational goals. However, when talking about the co-ordination, they show less spirit to work with diverse groups. Employees accepted that that do not have strong level of co-ordination among them. Approximately $50 \%$ of respondents said that employees from diverse cultures do not have such strong level of co-operation among them. Such resposne is very harmful for the organizational culture. It can prove as barrier in smooth functioning of any organization.

Employees also make infrequent negotiations as $58 \%$ of respondents said they negotiate only in meetings and other formal arrangements. Their negotiation is confined up to requirements of organization but they do not have effective way to communication within team to achieve the organizational goals.

Talking about collaboration, the employees had also discouraging figures to reveal. Majority approximately 55\% of employees said that they are not working in collorative way. In organization the formal work is done some extent in collaborative manner but employees said that organization's culture is not as collaborative as it must be. Employees also submitted that they can not solve their conflicts within team untill and unless there is interferance from third party. Almost $53 \%$ of respondents said that they are unable to solve their inter team conflicts. However, $39 \%$ of respondents said that they can solve their conflicts when arise among the employees of team. In the same context, employees also avoid to listen each other's ideas as they do not welcome new and creative ideas from the people of diverse cultures. Information taken from employees also shows that employees who are working in same group and belong to same culture have strong level of support for each other but employees working in group and belonging to different culture show less support of each other. Majority as 53\% of employees said that they do not support to other's in performing their work. They are confined to their own work.

\subsection{Co-relational Analysis}

The study also shows some correlation among the different variables. As nature of study is to identify the impact of cultural diversity on organizational productivity, therefore it is necessary to include correlation analysis in the study. The variables used in the study are cultural tolerance, cultural sensitivity, professional attitude, motivation and job security and team work.

The following table shows the relationship between the variables. 
Table 1: Correlation of Variables

\begin{tabular}{|l|c|c|c|c|c|}
\hline Variables & $\begin{array}{l}\text { Cultural } \\
\text { Tolerance }\end{array}$ & $\begin{array}{l}\text { Cultural } \\
\text { Sensitivity }\end{array}$ & $\begin{array}{l}\text { Professional } \\
\text { Attitude }\end{array}$ & $\begin{array}{l}\text { Motivation } \\
\text { and Job } \\
\text { Security }\end{array}$ & $\begin{array}{l}\text { Team } \\
\text { Work }\end{array}$ \\
\hline $\begin{array}{l}\text { Cultural } \\
\text { Tolerance }\end{array}$ & 1 & $-0.05\left(^{*}\right)$ & -0.241 & -0.161 & $0.06\left(^{*}\right)$ \\
\hline $\begin{array}{l}\text { Cultural } \\
\text { Sensitivity }\end{array}$ & $-0.05\left(^{*}\right)$ & 1 & 0.131 & -0.145 & -0.069 \\
\hline $\begin{array}{l}\text { Professional } \\
\text { Attitude }\end{array}$ & 0.241 & 0.131 & 1 & 0.091 & 0.231 \\
\hline $\begin{array}{l}\text { Motivation } \\
\text { and Job }\end{array}$ & & & & & \\
Security & 0.161 & -0.145 & 0.091 & 1 & 0.263 \\
\hline Team Work & $0.06\left(^{*}\right)$ & -0.069 & 0.231 & 0.263 & 1 \\
\hline
\end{tabular}

* Correlation is significant at the 0.05 level.

The table shows the negative or inverse correlation between cultural tolerance and cultural sensitivity which indicates that increase in the cultural tolerance would definitely decrease the cultural sensitivity. On the other hand, there is positive correlation between cultural tolerance and team work which indicates that increase in cultural tolerance may increase sprit for team work for achieving common goals of the organization.

\section{Conclusion}

The study clearly concludes that people living in Quetta are highly culturally sensitive and possess low cultural tolerance which is resulting in negative effect on organizational objectives as employees must have common goals to achieve when working in team form. Employees are often reluctant to work with the other employees who are belonging to different cultures. This can definitely makes the work of Human Resource Management more complex. Employees always are against the view that diverse work groups are best performers and result oriented. They try to support the employees belonging to their own culture to be selected for organizational jobs. This attitude can put negative impact on organization's objective and leads to low productivity and ineffectiveness.

People are highly sensitive in the area as they can't solve even their minor conflicts with the employees of other cultures. While interviewing with different employees, the researcher asked about the methodology of resolution of conflicts, the employees responded that they go often to third party when they feel necessary to solve the conflict arise among employees of diverse cultures. There is no effective way of making acknowledgment to good work of employees who is belonging from the diverse groups. The reason behind this attitude is that 
employees don't want to motivate their colleagues of diverse cultures as they fear that motivation can increase their work performance which results in more reward and promotion for them. As employees don't want to see the individual(s) on the top position belonging to other cultures therefore sense of motivation and acknowledgment is relatively low.

Researcher has identified that in certain circumstances there was co-operation among the individuals of different cultures. This happens when employees are given task collectively and performance measurement is on the basis of group performance. The co-operation really lacks in different organizations when employees are given individual tasks. The nomination of group leader also matters and hence put influence on co-operation among employees working in different organizations. Employees are not ready to train other employees of diverse cultures as they think that it is very difficult task to perform. However they are ready to train the employees who are from their own culture.

Cultural diversity has also negative impact on the employees working in the organization located in Quetta. Employees have fear that their job is not secure with the presence of those employees who are belonging to other cultures. Since all organizations are practicing the Equal Employment Opportunities, therefore, there is always chance for employees of diverse cultural groups to be selected for organizational jobs. Organizations try their level best to promote the employees on merit and there are clear cut policies to announce promotion for the deserving employees. For getting promotions, employees try to improve their skills but they are always reluctant to improve their skills by working employees of other culture. This thinking can lessen the spirit to strive for acquiring more and more skills in less span of time.

The conclusion show drastic figures relating to team work. Employees are working for common achievement of goals of the organization but it seems lack of co-ordination and communication among them. The nature of work specified in policies is collaborative but in real term is it not at all. In the case of any conflict within a team, the employees are not ready to listen each other's ideas. The team members are strongly lacking in support to each other. These attitudes within teams have very negative and long term impact on the whole productivity of the organization.

On the whole it can be concluded that employees working in different sectors of economy within Quetta are highly culturally sensitive which results in low cultural tolerance. Employees often show low professional attitude towards their work in terms of co-operation and respect when they are working with diverse work groups. Employees also receive low motivation from their co-workers of diverse groups. The team work methodology is very discouraging as there is no co-operation and communication among employees. Collaborative working patterns are not followed strictly by employees that ultimately influence the productivity of whole of organization. 


\section{Acknowledgement}

My first and foremost thanks are due to my respected colleagues Dr. Aftab Ahmed Shaikh, Ghulam Ali Mashori and Musarrat Karramat who provided every assistance and guidance during this research work. They provided their valuable suggestions during the preparation of this research paper.

I would also convey thanks to employees of Educational, Banking and NGOs sector in Quetta, who provided their great support and helped me to accomplish this task.

Finally, many thanks go to my colleagues and friends who gave their inputs and improved the quality of this research work.

\section{References}

[1] Eboni G. Price and Aysegul Gozu, "Role of Cultural Diversity in Recruitment, Promotion and Retention of Faculty in Academic Medicine", Journal of General Internal Medicine, vol 120, no. 7, (2005), pages 565571

[2] Cox T, "Cultural Diversity in Organizations: Theory, Research and Practice". San Transco: Berrett Koehler (1994),

[3] Hayles R.V and Russel, "The Diversity Directive: Why Some Initiatives Fail and What to do about it. (1997), Chicago: Irwin".

[4] Kossek K, E.E and Lobel S, Managing Diversity: Human Resources Strategies for Transforming the Work Place" Blackwell Synergy Publishing. (1996).

[5] Maj Molly K. "Understanding the Impact of Cultural Diversity on Organizations". The Research Department Air Command and Staff College, (1997).

[6] Robin J. Ely and David A. Thomas, "Cultural Diversity at Work Place. The Effects of Diversity on Work Group Processes and outcomes", Journal of Administrative Sciences, vol 46, No. 2, (2001), Jstore Publications. 